\title{
Radiation-Related Sarcoma
}

National Cancer Institute

\section{Source}

National Cancer Institute. Radiation-Related Sarcoma. NCI Thesaurus. Code C93125.

A sarcoma that arises in the bones or soft tissues following exposure to ionizing or nonionizing radiation. 